\title{
RESPUESTA PRODUCTIVA DE UN CULTIVO DE SANDÍA EN INVERNADERO CON USO DE AGUA DESALADA FRENTE AL AGUA DE POZO.
}

Marín Membrive, P.; Valera Martínez, D. L.; Reca Cardeña, J.; Moreno Teruel, M.A.; Peña Fernández, A.A.; Martínez López, J CIAIMBITAL, Universidad de Almería. jreca@ual.es

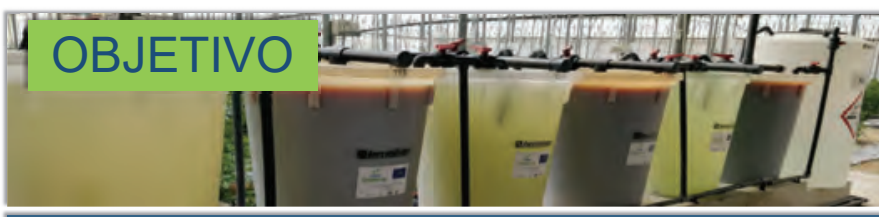

Estudiar experimentalmente el efecto del riego con agua de mar desalada sobre la producción y la calidad del fruto de un cultivo de sandia de invernadero en comparación con el uso de agua subterránea de un pozo de la zona del "Campo de Nijar" (Almería)

\section{RESULTADOS}

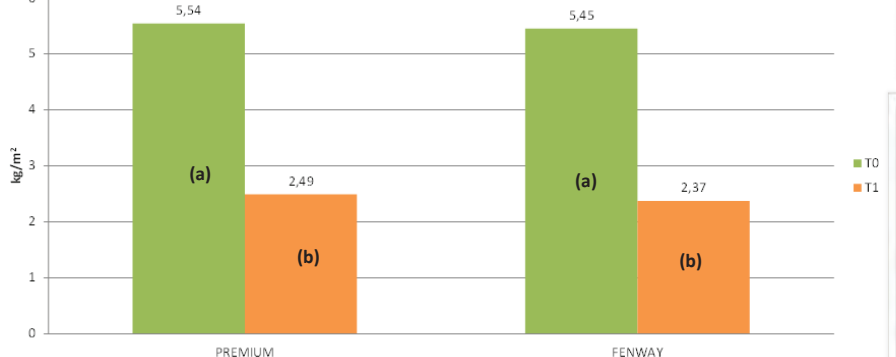

\begin{tabular}{|lcccccc|} 
& $\begin{array}{c}\text { Peso } \\
\text { T0 }\end{array}$ & $\begin{array}{c}\text { Peso } \\
\text { T1 }\end{array}$ & $\begin{array}{c}{ }^{\circ} \text { Brix } \\
\text { T0 }\end{array}$ & $\begin{array}{c}{ }^{\circ} \text { Brix } \\
\text { T1 }\end{array}$ & $\begin{array}{c}\text { Firmeza } \\
\text { T0 }\end{array}$ & $\begin{array}{c}\text { Firmeza } \\
\text { T1 }\end{array}$ \\
\hline Promedio & 6,76 & 5,12 & 12,03 & 11,68 & 0,93 & 0,87 \\
\hline Desviación Estándar & 1,00 & 1,25 & 0,70 & 0,71 & 0,17 & 0,10 \\
\hline $\begin{array}{l}\text { Coeficiente de } \\
\text { Variación }\end{array}$ & $14,85 \%$ & $24,52 \%$ & $5,80 \%$ & $6,08 \%$ & $17,79 \%$ & $10,94 \%$ \\
\hline Mínimo & 5,11 & 2,97 & 10,20 & 10,30 & 0,64 & 0,71 \\
\hline Máximo & 9,12 & 6,70 & 13,00 & 12,90 & 1,19 & 1,07 \\
\hline Rango & 4,01 & 3,73 & 2,80 & 2,60 & 0,55 & 0,36 \\
\hline Sesgo Estandarizado & 0,85 & $-0,82$ & $-1,92$ & $-0,69$ & 0,03 & 0,51 \\
\hline $\begin{array}{l}\text { Curtosis } \\
\text { Estandarizada }\end{array}$ & 0,20 & $-1,14$ & 1,84 & 0,38 & $-0,60$ & 0,03 \\
\hline
\end{tabular}

Se encontraron diferencias significativas en la producción, peso, y tamaño del fruto a favor tratamiento TO. En cuanto a parámetros de calidad ( ${ }^{\circ}$ Brix, firmeza), no se encontraron diferencias significativas entre tratamientos.
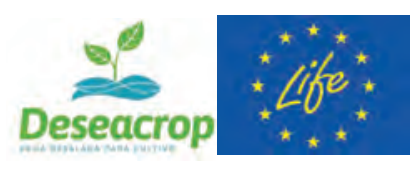
Proyecto financiado por el programa LIFE+ de la
Unión Europea (LIFE16-ENV-ES-000341) (4) http://www.deseacrop.eu/
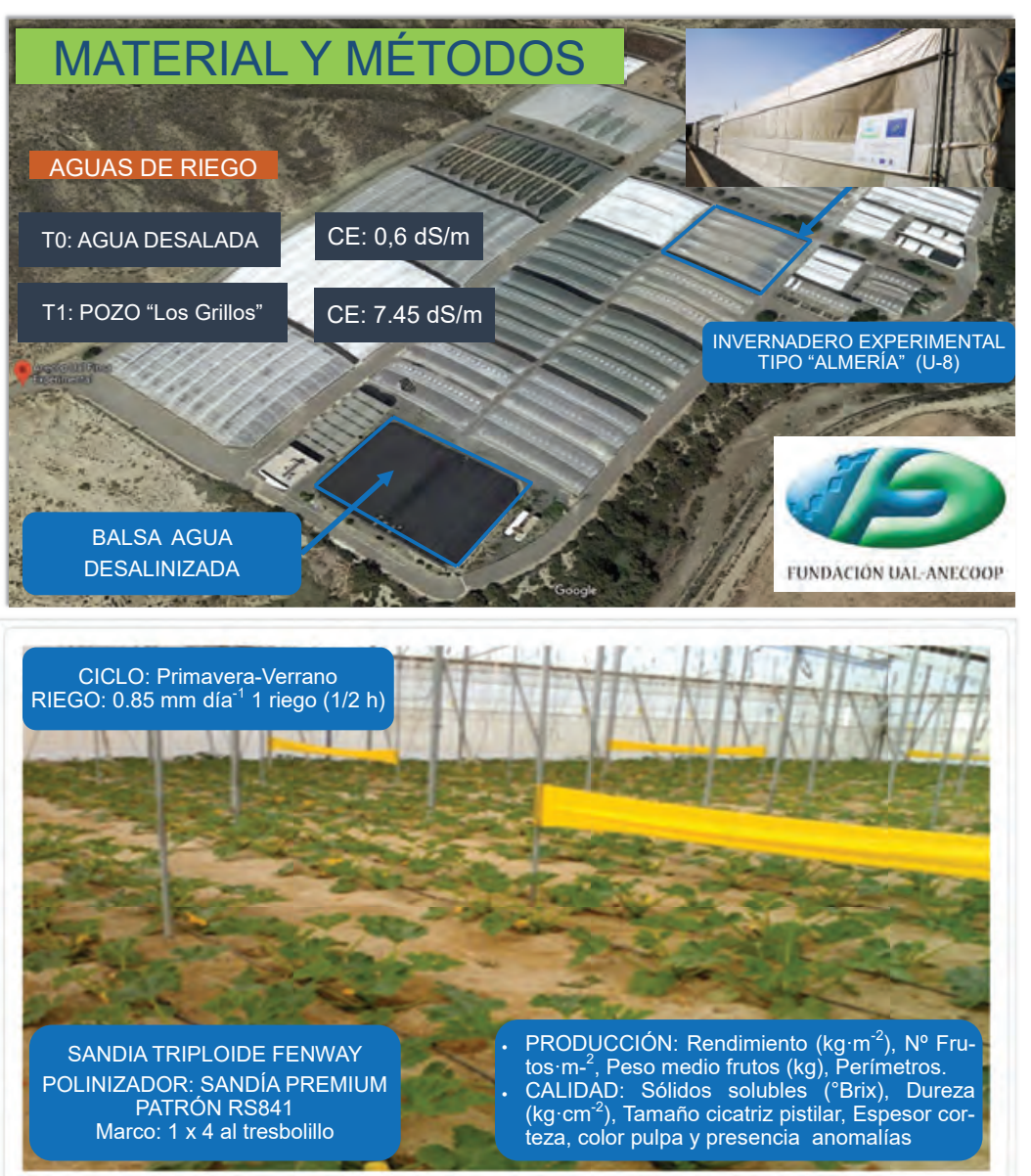

\section{CONCLUSIONES}

El uso del agua desalada proporcionó un incremento significativo (65\%) de la producción de sandía respecto al tratamiento regado con agua de pozo. Por el contrario, no se observó un efecto significativo sobre los parámetros de calidad del fruto.

El uso del agua desalada puede resultar económicamente rentable ya que e aumento de producción compensa el mayor coste del agua desalada para el riego de la sandia.

La aplicación de agua desalada contribuye a la sostenibilidad de los cultivos en invernadero y permite contrarrestar la sobreexplotación de los acuíferos y su alarmante salinización. RIDESOST. "Sostenibilidad agro-fisiológica, ambiental y económica del riego
con agua marina desalinizada en cultivos hortícolas de invernadero y en sistemas hidropónicos semicerrados". AGL2017-85857-C2-1-R

\begin{tabular}{|c|c|}
\hline 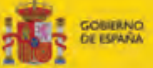 & 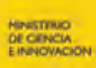 \\
\hline
\end{tabular}

